\title{
El Acorde de Tristán y la idea afortunada de Schopenhauer
}

\author{
Ana Paulina Rivero Hinojosa \\ Universidad Nacional Autónoma de México
}

Resumen: En el siglo XIX, el acercamiento entre la música y la filosofia fue tan intenso que se hizo notable. Esta investigación explora la influencia de la filosofia de Arthur Schopenhauer sobre la composición musical de Tristán e Isolda, un drama musical del compositor Richard Wagner. Se toman como punto de partida los textos del compositor en donde afirma haber conocido la obra filosófica de Schopenhauer y asegura que esta fue de gran importancia en su vida y en su labor artística. Este artículo sugiere que Wagner trató de representar la metafísica de Schopenhauer en su música.

Palabras clave: Wagner; voluntad; metafísica; estética; música.

Abstract: "The Tristan Chord and Schopenhauer's Lucky Idea". In the 19th century, the rapprochement between music and philosophy was so intense that it became noteworthy. This paper explores the influence of Arthur Schopenhauer's philosophy on Richard Wagner's musical composition Tristan and Isolde. It takes as starting point Wagner's texts where he claims to know Schopenhauer's philosophy, and endorses its influence in his life and his artistic labour. This article suggests that Wagner tried to represent Schopenhauer's metaphysics in his music.

Keywords: Wagner, will, metaphysics, aesthetics, music 
What is the most resilient parasite?

Bacteria? A virus? An intestinal worm?

An idea. Resilient... highly contagious.

Once an idea has taken hold of the brain

it's almost impossible to eradicate

An idea that is fully formed - fully understood - that sticks; right in there somewhere ${ }^{1}$.

\section{Introducción: Una idea afortunada}

El objetivo fundamental de este trabajo es investigar si la propuesta metafísico-estética de Arthur Schopenhauer influenció de manera significativa en la composición musical de Tristán e Isolda ${ }^{2}$, una de las principales obras de Richard Wagner.

Hablar de la relación entre música y filosofia es todo un reto porque cada cual es ya por sí sola bastante extensa y compleja y, aunque han tenido varios encuentros a lo largo de la historia, solo algunos han sido verdaderamente afortunados o relevantes. Además, se ha escrito tanta música y filosofia en general que el conjunto donde coinciden es reducido. Sin embargo, poner atención en la música ha implicado una gran expansión del campo de estudio de la filosofia y, si bien es cierto que actualmente existe una línea de investigación filosófica que se ocupa exclusivamente de la música ${ }^{3}$, la relación de estos dos colosales aspectos de la cultura puede explorarse todavía mucho más y aportar información muy significativa sobre el desarrollo cultural de la humanidad. Pareciera que tanto en la música como en la filosofia el espacio se desvanece dejando solo un tiempo en donde los sonidos, las palabras y las

\footnotetext{
1 Nolan, C., Inception, 2010. El diálogo completo reza: “¿Cuál es el parásito más resistente? ¿Una bacteria? ¿Un virus? ¿Un gusano intestinal? Una idea. Resistente... altamente contagiosa. Una vez que una idea se apodera del cerebro, es casi imposible erradicarla. Una idea que está totalmente formada — entendida por completo—, se adhiere; justo ahí, en algún lugar". La traducción es mía.

2 Tristán e Isolda es un drama musical en tres actos compuesto por Richard Wagner, quien también escribió el libreto, como solía hacerlo con todos sus dramas. Este drama se estrenó el 10 de junio de 1865 en Múnich.

3 Cf., Millet, J., "Una perspectiva sobre la filosofia de la música", en: Teorema: Revista internacional de filosofia, v. XXXI, 3 (2012), pp. 5-24
} 
ideas se desbordan hasta el infinito. ¿Cómo podría semejante desbordamiento llegar a ser explorado por completo?

Definitivamente la intención de esta investigación no es exponer de una vez y para siempre todo lo que hay que decir sobre la relación entre la música y la filosofia. Este proyecto es, más bien, una aventura acompañada de una propuesta aventurada: descubrir qué tanto pudo influir la filosofia de Schopenhauer en la composición musical de Tristán e Isolda de Richard Wagner. Tal vez descubramos, con sorpresa, que una nueva música y nuevas tendencias estéticas se originaron en parte de una idea afortunada y presente en El mundo como voluntad y representación.

Esta investigación se basa en que, si bien "nadie antes que Schopenhauer había dedicado en la historia del pensamiento [filosófico] una atención tan preeminente a la música, y nadie tampoco le había asignado un papel más relevante" , la influencia que tuvo sobre Wagner no se debe única ni exclusivamente al tratamiento que hace de la música, sino principalmente a su propuesta metafísica ${ }^{5}$. A decir verdad, parece que Wagner fue influenciado más por la metafisica de Schopenhauer que por su estética o sus inclinaciones musicales. Casi podría decirse que la estética schopenhaueriana no tiene sentido si se piensa de manera independiente a su metafísica. A fin de cuentas, la filosofia de Schopenhauer se reduce a un único pensamiento -como afirma el propio autor-, por lo que tal vez no sea tan errado afirmar que su metafísica y su estética resultan ser una y la misma cosa, al menos en el ideal schopenhaueriano. En El mundo como voluntad y representación, Schopenhauer expone diversos aspectos de su pensamiento y cómo este se desarrolla y entiende en diversos ámbitos, tales como el metafisico, el estético y el ético. Aunque esta investigación está dedicada en gran parte al tratamiento que Schopenhauer ofrece de la música, será necesario entender la propuesta fundamental de Schopenhauer pues, como se ha dicho, no es posible entender su estética si no se ha comprendido su metafísica.

Ahora bien, entender la propuesta fundamental de Schopenhauer puede ser una tarea muy demandante. No solo por el hecho de que hay varios prerequisitos para acercarse a su obra (entre los cuales hay una extensa lista de

\footnotetext{
4 Pérez, E., El Wagner de las ideologías: Nietzsche-Wagner, Madrid: Biblioteca Nueva, 2004, p. 112 .

5 Cf., Brener, M., Wagner and Schopenhauer: A Closer Look, Xlibris LLC, 2014; Magee, B., Wagner y la filosofia, México: Fondo de Cultura Económica, 2011, y Pérez, E., El Wagner de las ideologias, 2004.
} 
lecturas sugeridas al lector), sino porque al leerla no es fácil saber con qué actitud acercarse a ella, si filosófica o dramática ${ }^{6}$.

Para entender a Schopenhauer, debemos tener en cuenta tres aspectos fundamentales del hombre: el cuerpo, el sentimiento y la razón. Su filosofia está, por así decirlo, encarnada en la corporalidad y se debe pensar necesariamente desde nuestro cuerpo, que no se basa en la formalidad del pensamiento, sino en las inclinaciones y en la capacidad de anhelar propias de cada individuo. Aunado a lo anterior, cabe decir que la filosofia de Schopenhauer debe leerse con sentimiento y con seriedad a la vez. Su obra no es ni un sistema conceptual arquitectónicamente estructurado ni una obra literaria; para leerla ha de encontrarse un punto de equilibrio entre ambos extremos. A fin de cuentas, es una filosofia que nos pide ver el mundo como dos realidades: como voluntad y como representación.

Muchos de los que han escrito sobre Schopenhauer resaltan las palabras del autor cuando afirma que en El mundo como voluntad y representación está expresado un único pensamiento. Incluso algunos han buscado en dicha obra una sentencia que lo contenga o lo sintetice, pero tal vez no sea necesario buscarla ya que uno de los sentidos en los que puede hablarse de un único pensamiento es afirmando que Schopenhauer expone la unidad de su pensamiento.

Dicho lo anterior, es conveniente, al menos para los fines de esta investigación, ver a la filosofia schopenhaueriana como una unidad porque así podrá entenderse la relación de su metafísica con su estética musical: las implicaciones de una también lo serán de la otra. De hecho, puede afirmarse que de todos los temas que aborda Schopenhauer la música es precisamente el que está más ligado a su metafísica ya que, para él, la música es "una copia inmediata de la voluntad misma y representa lo metafísico de todo lo físico del mundo, la cosa en sí de todo fenómeno. Por lo tanto, podríamos igualmente llamar al mundo música hecha cuerpo o voluntad hecha cuerpo"7; incluso (y yendo aun más lejos), hay quienes afirman, con cierta ironía, que la obra capital del filósofo bien pudo haberse llamado El mundo como música y representación ${ }^{8}$ y el sentido del título habría sido el mismo

6 Cf., Philonenko, A., Schopenhauer: una filosofia de la tragedia, Barcelona: Anthropos, 1989, pp. $9-50$.

Schopenhauer, A., El mundo como voluntad y representación, v. I, Madrid: Gredos, 2014, p. 310 .

8 Philonenko, A., Schopenhauer, p. 216. 
La filosofia de Schopenhauer es un organismo en tanto todas y cada una de las partes que la conforman son inalienables e inalterables, es decir, su pensamiento está vertido en todas las sentencias de su obra como la funcionalidad de nuestro cuerpo lo está en todos nuestros órganos, mientras que la idea de que "este mundo en que vivimos y estamos es, en cuanto a su esencia, enteramente voluntad y al mismo tiempo enteramente representación" es el punto de partida (como lo fue para nosotros el ser concebidos), es ese einziger glücklicher Einfall (una única idea afortunada) que abre la brecha a un único pensamiento. Partamos, entonces, de la idea de que este mundo es representación y al mismo tiempo es voluntad. ¿Cómo debe entenderse semejante distinción?

\section{La metafisica de Schopenhauer: un afán de deseo incontenible}

"La filosofia siempre ha sabido que debía ser una ciencia no solo de lo claro y lo distinto, sino también de lo confuso"9: Schopenhauer sabía que su filosofia no debía tratar solo de la claridad y distinción, sino también de lo opaco e invisible y de las irremediables incongruencias de la vida y su carácter trágico. Partiendo de la pregunta por aquello que está más allá del mundo fenoménico, el autor llega a la conclusión de que cierta voluntad, cierto afán ciego e incontenible se encuentra allí donde termina el fenómeno; alli donde el mundo deja de ser representación, es voluntad. Como ya se ha dicho antes, la filosofia schopenhaueriana es una unidad orgánica que parte de una idea fundamental: el mundo es $\mathrm{mi}^{10}$ voluntad y mi representación: "Schopenhauer... distingue entre el conocimiento según el Principio de Razón, lo que él llama 'representación', y la forma intima, ligada al cuerpo, de entender la naturaleza desde dentro. Solo en mí mismo, dice Schopenhauer, experimento lo que es el mundo más allá de lo que a mí se me da en la representación"11. Su metafísica está implícita en esta idea y, a decir verdad, la gran contribución que hace Schopenhauer al pensamiento del siglo XIX es precisamente su concepción de la voluntad como "un poder oscuro de la vida que actúa en el hombre igual que

9 Ibid., p. 284.

10 El pronombre posesivo de primera persona singular da el matiz necesario para comprender que la filosofia de Schopenhauer está incrustada en la corporalidad humana. La palabra "voluntad" con que nos referimos a esa fuerza presente en todo lo que existe es una especie de sinécdoque; llamamos voluntad a dicha fuerza porque no podemos tener conciencia de ella más que en una de sus formas o partes: nuestra propia voluntad. Véase el parágrafo 22 del primer tomo de El mundo como voluntad y representación.

11 Safranski, R., Romanticismo: una odisea del espiritu alemán, México: Tusquets, 2009, p. 106. 
en la naturaleza entera"12. La metafísica de Schopenhauer pretende responder, antes que nada, a una necesidad humana.

Schopenhauer se considera discípulo de Kant. De hecho, se considera a sí mismo como el perfeccionador de las doctrinas kantianas. A razón de esto, algunos autores han afirmado que la mejor manera de explicar a Schopenhauer es entendiendo primero a Kant ${ }^{13}$. La influencia de este en nuestro filósofo es enorme. Incluso puede afirmarse que la propuesta schopenhaueriana se sostiene sobre la distinción kantiana entre fenómeno y cosa en $s i^{14}$.

Para Schopenhauer, el mundo tiene dos dimensiones: como representación y como voluntad. La diferencia fundamental entre ambas es que la primera está regida por el Principio de Razón Suficiente y la segunda no lo está, es decir, "lo que es el mundo, además de ser mi representación, es para Schopenhauer la voluntad experimentada en el propio cuerpo"15. Sabiendo que el pensamiento schopenhaueriano es deudor del de Kant, la idea de equiparar la distinción entre fenómeno y cosa en sí con la distinción entre el mundo como representación y como voluntad puede ser atractiva. El fenómeno es propio del mundo visto como representación mientras que la cosa en sí es, en la propuesta schopenhaueriana, nada más y nada menos que la voluntad. Sin embargo, para Schopenhauer, Kant no está libre de errores: "el mundo es, por una parte, representación, y nada más que eso, y, por otra parte, solamente voluntad. Pero una realidad que no fuera ninguno de estos dos lados, sino que fuera un objeto en sí (y a esta condición se le redujo desgraciadamente a Kant la cosa en sí), es una quimera soñada y su supuesto un fuego fatuo de la filosofia"16.

Será justamente en la caracterización de la cosa en sí donde Schopenhauer pretenderá "corregirle la plana" a Kant. Aunque la distinción kantiana entre fenómeno y cosa en sí da lugar al mundo como voluntad y como representación, aunque articula precisamente la obra capital de Schopenhauer -pues la voluntad, considerada como cosa en sí, es completamente distinta de su propio fenómeno y a la vez completamente libre de toda forma fenoménica ${ }^{17}$ - hay al menos una característica que no comparten la voluntad y la cosa en sí: es la posibilidad de conocer a la primera mientras que la segunda está totalmente

12 Ibid., p. 107.

${ }^{13}$ Magee, B., Schopenhauer, 1991.

${ }^{14}$ Janaway, Ch., Schopenhauer: a Very Short Introduction, Nueva York: Oxford University Press, 2002.

${ }^{15}$ Safranski, R., Romanticismo, p. 106.

${ }^{16}$ Schopenhauer, A., El mundo como voluntad y representación, v. I, p. 5.

${ }^{17}$ Ibid., p. 134. 
fuera de nuestro alcance. Atendiendo a esta cuestión, he aquí un extracto del segundo tomo de El mundo como voluntad y representación: "En el camino del conocimiento objetivo, es decir, el que parte de la representación, nunca se irá más allá de la representación, o sea, del fenómeno; se permanecerá siempre en el lado externo de las cosas, sin poder penetrar y explorar su interior, lo que son en sí mismas, o sea, para sí mismas. Hasta aquí estoy de acuerdo con Kant. Ahora bien, como contrapeso de esta verdad he subrayado esta otra: que nosotros no somos meramente el sujeto cognoscente, sino que, por otro lado, también nos contamos entre los seres cognoscibles y somos la cosa en sí; que, por consiguiente, para llegar a esa esencia propia e interna de las cosas, en la que no podemos penetrar desde el exterior, se nos abre un camino desde el interior, en cierto modo, un pasadizo subterráneo, un enlace secreto que directamente nos conduce como por una traición a esa fortaleza que no podemos tomar atacándola desde fuera. Solo de modo inmediato puede la cosa en sícomo tal entrar en la conciencia, y es haciéndose consciente de sí misma. Querer conocerla objetivamente es pretender algo contradictorio. Todo lo objetivo es representación, es decir, manifestación, mero fenómeno cerebral"18.

Somos la cosa en sí. Por esa razón, para Schopenhauer sí es posible conocerla en tanto tomamos conciencia de nosotros mismos como algo más que representación y tal conocimiento solo es posible desde el propio cuerpo, pues "no se puede llegar a la esencia de las cosas desde fuera; se investigue de un modo o de otro, no se obtienen otras cosas que imágenes y nombres... por el contrario, el concepto de voluntad es el único entre todos los posibles que no tiene su origen en el fenómeno, que no lo tiene en la mera representación intuitiva, sino que proviene del interior, que brota de la conciencia más inmediata de cada uno, en la cual cada uno se conoce y al mismo tiempo es su propio individuo según su esencia, inmediatamente, sin forma alguna, incluso sin las de sujeto y objeto, pues aquí lo cognoscente y lo conocido coinciden"19.

Reconocemos en nosotros cierta "fuerza" a la que llamamos voluntad. En ella radica nuestra esencia y en ella radica la esencia de todas las cosas. La cosa en sí es aquello que ya no es representación y que, por ello, no es accesible al conocimiento "externo". Solo reconociéndola en nosotros mismos podemos, de cierta forma, conocerla. Esta condición del mundo y de nosotros mismos genera sufrimiento porque la esencia de las cosas radica en un deseo

\footnotetext{
18 Schopenhauer, A., El mundo como voluntad y representación, v. II, Madrid: Gredos, 2014, pp. 118-119.

19 Schopenhauer, A., El mundo como voluntad y representación, v. I, p. 118 y p. 133.
} 
insaciable y a la vez incontenible que nunca da lugar a la plena satisfacción de nuestros deseos.

Schopenhauer afirma que la voluntad como cosa en sí es totalmente distinta de su fenómeno y está libre de todas las formas fenoménicas en las que ingresa al manifestarse, formas que por ello afectan únicamente a su objetividad, pero le son ajenas en sí misma, pues ella misma es una. La voluntad es ajena a las condiciones de conocimiento a las que está sometida la representación, se encuentra fuera del tiempo y del espacio, fuera del principio de individuación, fuera del Principio de Razón Suficiente, no tiene fundamento ni finalidad.

\section{La estética de Schopenhauer: la música y otras artes}

Una vez explicado someramente de dónde proviene el concepto de voluntad de Schopenhauer estamos algo mejor preparados para entender por qué Philonenko sugiere, jugando un poco con los términos, que "música" bien puede ser equivalente a "voluntad".

Ya se ha hablado más arriba de lo íntimamente relacionadas que están la estética y la metafísica schopenhauerianas. Cualquier división de la filosofia de Schopenhauer que implique tener por un lado a la metafisica y por otro a la estética será poco conveniente en esta investigación, así que debemos hablar de su estética sin dejar de lado a su metafisica, pues planteamos que es imposible entender a la primera sin la segunda.

En el libro tercero de El mundo como voluntad y representación, Schopenhauer expone una detallada jerarquía de las artes según el grado de objetivación de la voluntad que hay en ellas (desde la arquitectura hasta la tragedia(. Sin embargo, la música es excluida de esta jerarquía y ello se debe, según el propio autor, a que "en el contexto sistemático de la exposición [de esa jerarquía] no había para ella un lugar adecuado"20. Para Schopenhauer la música se cuenta aparte del resto de las artes y tiene su propia caracterización: "En la música no reconocemos la copia, la reproducción de idea alguna de los seres del mundo; sin embargo, es un arte tan elevado y grandioso, y actúa tan poderosamente en lo más interior del hombre, y este lo entiende de manera tan completa y profunda, que constituye un lenguaje universal cuya claridad supera incluso a la del propio mundo intuitivo"21.

${ }^{20}$ Ibid., p. 302.
${ }^{21}$ Ibid.

ARETÉ Revista de Filosofía, v. XXXII, 1, 2020 / ISSN 1016-913X 
El §52 de El mundo como voluntad y representación (el último parágrafo del libro tercero) está enteramente dedicado a la música, así como el capítulo 39 de los Complementos. Schopenhauer considera que este arte se aparta de los demás ${ }^{22}$-que son objetivación de la voluntad- porque en cierto modo la música es la voluntad misma: en ella hay una "significación seria y profunda" que hace referencia a la esencia del mundo y del hombre y, aunque el efecto de la música sea muy similar al de las demás artes, su efecto es más intenso y familiar, necesario e infalible. Cualquier persona puede comprender al instante su íntima relación con el mundo, basta con la comprensión inmediata que se tiene de ella al escucharla. Concedamos la supremacía de la música sobre las demás artes, concedamos que cualquier persona puede comprender su relación con el mundo y que su impacto en el hombre es mucho más intenso que el de las demás artes. Aun así, cabría preguntarse qué es lo que hace a la música ser tan especial y por qué, si cualquiera la comprende, no cualquiera la compone.

Es verdad que el lector no está obligado a aceptar la explicación que ofrece Schopenhauer sobre la música, pues ello depende de qué tanto comprendemos y abrazamos su propuesta metafísica y qué cosa es para cada cual la música. Sin embargo, vale la pena entender qué es la música para Schopenhauer porque, tal vez sin pretenderlo, dio la pauta teórica para una composición musical concreta: el Tristán e Isolda de Richard Wagner.

Para entrar de lleno a la estética musical de Schopenhauer, recordemos lo que se mencionó más arriba: que la representación, en contraposición a la voluntad, está sometida al Principio de Razón y solo lo que está sometido a tal principio puede ser llamado propiamente "objeto", porque un objeto es aquello que puede ser conocido por un sujeto, aquello que es representación. En cambio, la cosa en sí no puede ser conocida -al menos no de la misma forma que se conoce un objeto cualquiera- es decir, bajo determinaciones espacio-temporales. Veamos entonces qué sucede con la música y, de paso, con las demás artes, qué son y cómo se les conoce.

Así como Kant, Platón también influyó fuertemente en Schopenhauer. Este incluirá la teoría de las Ideas a su ecléctica filosofia afirmando que la idea platónica "es necesariamente objeto, algo conocido, una representación $\mathrm{y}$, precisamente por eso y solo por eso, se diferencia de la cosa en sí. La idea simplemente se ha deshecho de las formas subordinadas del fenómeno, que incluimos en su totalidad bajo el Principio de Razón o, mejor dicho, no ha

${ }^{22}$ Se refiere a la arquitectura, a la escultura, a la pintura y a la tragedia. 
entrado todavía en ellas"23. Sin embargo, el ser humano, en tanto individuo, no tiene ninguna posibilidad de conocer aquello que no esté sometido al Principio de Razón y, por tanto, no puede conocer a las ideas. Solo será posible "elevarse" del conocimiento de las cosas particulares al de las ideas por medio de cierta transformación en el sujeto, que implica dejar a un lado su condición de individuo. Cabe preguntarse: ¿cómo es posible que el humano deje a un lado su condición de individuo que desea y conoce solo conforme al Principio de Razón? ¿Cómo conocer un objeto determinado sin recurrir a la relación que este tiene con otros objetos? La pronta respuesta es contemplándolo, perdiéndose en él: "en tal contemplación, la cosa particular se convierte de golpe en idea de su especie, y el individuo en sujeto puro del conocer"24.

Lo que ha pasado entonces es que el individuo y el objeto se han transformado y el mundo como representación se manifiesta ahora de manera completa y pura, tiene lugar la "perfecta objetivación de la voluntad", tiene lugar un conocimiento completamente diferente al que aportan las ciencias naturales y las matemáticas: acontece el arte, la obra del genio, la cual tiene su origen en el conocimiento (contemplación) de las ideas y su finalidad es comunicar dicho conocimiento. Schopenhauer define el arte como "el modo de considerar las cosas independientemente del principio de razón” 25 pero, aunque tal definición es consecuente con el resto de su pensamiento, no deja de ser negativa en tanto que solo nos dice qué no es el arte.

Si las ideas son la adecuada objetivación de la voluntad, entonces las artes tienen el objetivo de propiciar el conocimiento de las ideas por medio de la representación de objetos particulares, es decir, las artes objetivan a la voluntad de manera indirecta por medio de las ideas. Sin embargo, no sucede lo mismo con la música pues esta trasciende las ideas y, dice Schopenhauer, es completamente independiente del mundo fenoménico. De hecho, ella "podría existir aunque el mundo no existiese, lo que no puede decirse de las demás artes"26. Mientras las demás artes son una reproducción de las ideas, la música es una reproducción de la voluntad misma. Más allá de jerarquizar y definir a la música, Schopenhauer aventura toda una concepción estética de cómo entender la música con sus propios términos, los cuales no son precisamente los de un músico, pero sí reflejan un profundo respeto por la música.

\footnotetext{
${ }^{23}$ Schopenhauer, A., El mundo como voluntad y representación, v. I, p. 206.

24 Ibid., p. 211.

25 Ibid., p. 128.

26 Schopenhauer, A., El mundo como voluntad y representación, v. II, p. 304.
} 
Schopenhauer expone una teoría musical basada en metáforas y juicios propios para exponer por qué la música es una forma en que se manifiesta la voluntad. Precisamente todo ese juego de metáforas es lo que hace tan interesantes los pasajes de Schopenhauer que tratan sobre música, no solo por lo atractivo del discurso y la densidad emocional, sino por lo que esas ideas ocasionaron en sus lectores. Todo lo que se ha expuesto hasta ahora es justamente lo que leyó Wagner en la obra de Schopenhauer: un discurso que reconoce una dualidad en el mundo -un entramado de apariencias por un lado y una compleja incomprensibilidad por el otro-, un continuo sufrimiento causado por un deseo incesante y una oda a las artes que corona a la música. Todo esto y mucho más fue lo que pudo haber encantado a Wagner cuando leyó a Schopenhauer27.

Eventualmente, los pasajes sobre música mencionados no están escritos para enseñar al lector qué es la música ni cómo escucharla. Leyendo El mundo como voluntad y representación no se aprenderá contrapunto ni armonía. La forma en que el autor habla de la música cobra mayor sentido dentro del propio pensamiento schopenhaueriano y el lector tendrá más claros dichos pasajes si ha comprendido la propuesta metafisica de Schopenhauer. De lo contrario, tales palabras pueden parecer carentes de relevancia estética. No debe olvidarse que el filósofo escribió sobre música desde su muy particular punto de vista y no pretendió cambiar el rumbo de la composición musical. Solo expuso su forma personal de escuchar y entender a la música. Sin embargo, esa forma tan particular de concebir a este arte y al mundo en general dejó una fuerte impresión en muchos pensadores, entre los cuales se encuentra el compositor Richard Wagner. Aunque efectivamente Schopenhauer no le enseñó a Wagner cómo debía componer, el filósofo sí sembró una idea en el compositor, una idea muy resistente y muy contagiosa que pudo ser lo que originó uno de los acordes más famosos en la historia de la música: el Acorde de Tristán.

\section{La música en Schopenhauer: metafisica en términos musicales}

Ahora bien, ¿es siquiera posible componer música en términos schopenhauerianos? La respuesta más obvia sería que no, puesto que, por mucho que supiera de teoría musical y tocara la flauta, Schopenhauer no era músico profesional ni tenía la intención de aleccionar a nadie sobre nada, especialmente no pretendía decirle a un compositor cómo hacer su trabajo. La intención del

${ }^{27}$ Wagner, R., Mi vida, Madrid: Turner, 1989.

ARETÉ Revista de Filosofía, v. XXXII, 1, 2020 / ISSN 1016-913X 
filósofo es, en palabras de Philonenko, "subrayar la dignidad" de la música al mostrar su carácter metafísico y su íntima relación con el mundo 28 .

Para Schopenhauer, la música está íntimamente ligada con la voluntad y, por tanto, con el mundo. Entre los pasajes donde pone en evidencia lo anterior destaca el siguiente: "La naturaleza del hombre consiste en que su voluntad aspira a algo, se satisface, aspira de nuevo, y así continuamente; su felicidad y su bienestar dependen de que el paso del deseo a la satisfacción y de esta a un nuevo deseo sea rápido, pues el retraso en la satisfacción produce dolor, y la falta de un nuevo deseo genera unas ansias vacias, languor ${ }^{29}$, tedio. En correspondencia con esto, la esencia de la melodía es una continua desviación, un errático alejamiento del tono fundamental por mil caminos; no solo llega a los intervalos armónicos, a la tercera o a la dominante, sino a cada tono, a disonante séptima y a los intervalos aumentados, pero para regresar siempre al tono fundamental. Todos esos caminos de la melodía expresan los deseos multiformes de la voluntad, pero regresando al cabo a un nivel armónico o, mejor, al tono fundamental, que representa la satisfacción"30. La sucesión de sonidos es equivalente, para el autor, a la sucesión de deseos. La sensación sonora producida por el cambio de una nota a otra es comparable al movimiento de nuestra voluntad a través de diversos objetos del deseo: un subir y bajar entre satisfacción e inconformidad. La esencia de la melodía ${ }^{31}$ radica en la diferencia de entonación entre un sonido y otro desplegados en el tiempo bajo un ritmo ${ }^{32}$ o, en palabras de Schopenhauer, "en la discordia y la reconciliación, siempre renovadas entre el elemento rítmico y el elemento armónico"33. Además del ritmo y la melodia, la música depende en gran medida de la armonía ${ }^{34}$. Respecto a este elemento musical, Schopenhauer escribió una serie de pasajes sorprendentes que no pueden sino entusiasmar y hundir en el más perfecto delirio a cualquiera que se sienta atraído por las artes sonoras. $\mathrm{El}$ autor compara los grados que conforman a un acorde con los grados de

\footnotetext{
${ }^{28}$ Philonenko, A., Schopenhauer, 1989.

29 Languidez.

30 Schopenhauer, A., El mundo como voluntad y representación, v. I, p. 307.

31 "La melodía es la sucesión de sonidos de diferente altura que, animados por el ritmo, expresan una idea musical” (Moncada, F., La más sencilla, útil y práctica teoría de la música, México: Ediciones Framong Musical Iberoamericana, 1966).

32 "El ritmo es el orden y la proporción en que se agrupan los sonidos en el tiempo" (Moncada, F., La más sencilla, útil y práctica teoría de la música).

${ }^{33}$ Schopenhauer, A., El mundo como voluntad y representación, v. II, p. 520.

34 "La armonía es la parte de la música que estudia la formación y combinación de acordes" (Moncada, F., La más sencilla, útil y práctica teoría de la música).
} 
objetivación de la voluntad en el mundo: "Las cuatro voces de toda armonía, es decir, bajo, tenor, contralto y soprano, o la nota fundamental, la tercera, la quinta y la octava, corresponden a los cuatro grados en la escala de los seres, es decir, a los reinos mineral, vegetal, animal y humano"35.

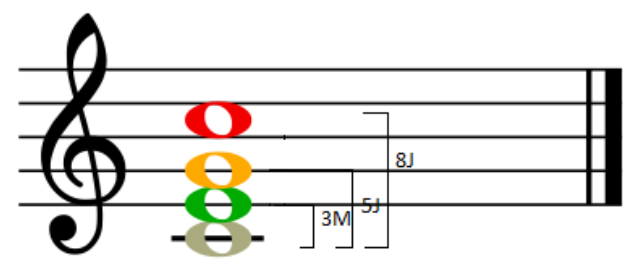

Ilustración 1: Acorde de Do M. La imagen de un acorde mayor que ilustra los cuatro grados a los que se refiere el autor. Imagen creada con MuseScore (2017)

La intima relación entre la voluntad y la música que señala Schopenhauer está justificada por la idea de que el movimiento de cada una de las voces corresponde a los movimientos volitivos presentes en cada grado de los seres: el mundo mineral mantiene cierta estabilidad así como la cuarta voz (en este caso el bajo) tiene menos cambios de altura; las plantas tienen mayor movimiento volitivo que los minerales en tanto que buscan los rayos del sol y nutrirse de la tierra para crecer; el reino animal (con mayor movimiento volitivo que las plantas) está en continua búsqueda de su alimento y seguridad; y el humano, además de buscar su alimento y seguridad, también sufre continuamente arrebatos de su voluntad, que pueden llevarlo hasta el más alto éxtasis o a la más profunda depresión. De la misma manera, en la música la voz superior es, por así decirlo, más libre que las demás, al poder subir y bajar con mucho mayor soltura que las otras y por ello suele ser la que lleva la melodía.

\section{Schopenhauer sobre el pentagrama: El Acorde de Tristán}

Si bien es cierto que todo lo que se ha expuesto hasta el momento sobre música en los términos schopenhauerianos puede sonar descabellado, sus ideas fueron muy bien recibidas por muchos filósofos y músicos. Gustav Mahler, por ejemplo, pensaba que El mundo como voluntad y representación "contenía el

${ }^{35}$ Schopenhauer, A., El mundo como voluntad y representación, v. II, p. 511.

ARETÉ Revista de Filosofía, v. XXXII, 1, 2020 / ISSN 1016-913X 
análisis más profundo sobre la música que jamás se hubiera hecho, comparable al artículo de Wagner sobre Beethoven"36. Además, estemos de acuerdo o no con la metafísica schopenhaueriana, podemos conceder, como oyentes, que "la música nos crea ciertos deseos que luego prolonga antes de satisfacerlos. Incluso la melodía más simple, una sucesión cualquiera de notas sueltas, hace que deseemos que a la larga concluya en la tónica, sin importar la amplitud de su recorrido antes de hacerlo, y puede provocar en nosotros una desconcertante insatisfacción si termina con otra nota distinta" ${ }^{37}$. La forma en que Schopenhauer habla de la música expresa una gran comprensión del sentir del oyente y de la intención del compositor. En ese sentido, sus palabras son un vínculo entre el creador y el receptor de la obra de arte sonora en general. Una de las figuras más sobresalientes del gremio artístico que abrazó su propuesta estética basada en la voluntad fue precisamente Richard Wagner, quien admitió repetidamente haber sido influenciado por Schopenhauer y fue un ferviente admirador hasta el final de su vida. En el otoño de 1854, Wagner leyó por primera vez El mundo como voluntad y representación: "En el pacífico silencio de mi casa, conocí un libro cuyo estudio llegó a ser de gran importancia para mí. Era Die Welt als Wille und Vorstellung (El mundo como voluntad y representación), de Arthur Schopenhauer. Herwegh me había hablado de este libro, que en cierto modo no se había descubierto hasta hace poco, aunque hayan transcurrido más de treinta años desde su primera publicación... Me sentí inmediatamente interesado por él y empecé a estudiarlo de inmediato... En realidad, ya me había impresionado el veredicto de un crítico inglés que, con toda franqueza, había confesado que su respeto vago pero poco convencido por la filosofia alemana habia sido atribuible a su absoluta incomprensibilidad, como así lo probaban las obras más recientes de Hegel; por otra parte, empero, al leer a Schopenhauer se percató de repente de que no había sido su propia escasez de luces lo que le habia causado ese desconcierto, sino la manera intencionalmente embrollada en la que se abordan las teorías filosóficas $^{38}$. Todo aquel que ha sido incitado a tener una gran pasión por la vida hará como yo hice, y buscará ante todo las conclusiones finales del sistema schopenhaueriano; mientras su forma de tratar la estética me complació

\footnotetext{
${ }^{36}$ Henry Louis de la Grange en Magee, B., Schopenhauer, p. 205.

37 Magee, B., Wagner y la filosofía, p. 214.

38 Se refiere al artículo "Iconoclasia en la filosofia alemana", que se publicó en abril de 1853 en la Westminster and Foreign Quarterly Review y que fue traducido al alemán en el periódico Vossische Zeitung.
} 
inmensamente -en particular su sorprendente y significativa concepción de la música-, me alarmaron, en cambio, como a cualquiera que tenga los mismos esquemas mentales que yo, los principios morales con los cuales remata su trabajo, porque presenta la aniquilación de la voluntad y el renunciamiento total como el único medio verdadero para redimirse de los vínculos restrictivos de la individualidad en su relación con el mundo"39.

La influencia de Schopenhauer en Wagner es un tema controversial entre los wagnerianos teóricos ${ }^{40}$. Muchos de ellos dedican gran parte de sus obras a dicha influencia matizándola, acentuándola o negándola ${ }^{41}$. Quien ha estudiado ampliamente a los dos personajes principales de esta investigación es Bryan Magee, quien ha publicado grandes trabajos sobre Schopenhauer y también sobre Wagner. Por esa razón, es uno de los teóricos más recurridos en el tema. Por otro lado, una reciente publicación de Milton E. Brener titulada Wagner and Schopenhauer: a closer look (2014) aporta gran perspectiva y matiz a la relación Schopenhauer-Wagner desde un punto de vista neutro y actual. La obra del músico Eduardo Pérez Maseda titulada El Wagner de las ideologías (2004) también es un recurso importante para entender la obra de Richard Wagner dentro de su contexto histórico. Por último, un reciente artículo de Alessandro Pinzani titulado "How much Schopenhauer is there really in Wagner?" (2012) es una excelente referencia sobre la influencia de Schopenhauer en la obra wagneriana ${ }^{42}$.

Pinzani sostiene que Parsifal es el único personaje de Wagner que parece ser verdaderamente schopenhaueriano, lo que no sucede ni con Tristán ni con Isolda. Además, si aceptamos que el libreto de Tristán e Isolda no tiene gran valor filosófico -como afirma Pinzani-, entonces cabe aquí la misma pregunta que él plantea en su artículo: ¿por qué este drama es considerado por muchos una obra de influencia schopenhaueriana? ${ }^{43}$. El autor se apega a la respuesta

\footnotetext{
39 Wagner, R., Mi vida, pp. 462-463.

40 Vale la pena resaltar que Wagner tuvo, además de Schopenhauer, otro vínculo importante con la filosofia occidental: Friedrich Nietzsche. Éste último también escribió sobre la influencia de Schopenhauer sobre Wagner. Sin embargo, la opinión de Nietzsche sobre Wagner no se abordará aquí debido a los alcances y limitaciones de esta investigación. Para conocer sobre el tema, véase El Wagner de las ideologías de Eduardo Pérez Maseda.

41 Thomas Mann, Ernest Newman, Ronald Tylor, John Chancellor son algunos de los que abordan la influencia que Schopenhauer ejerció sobre Wagner. Cf., Magee, B., Schopenhauer, p. 145.

${ }^{4} \mathrm{Si}$ bien es cierto que se ha escrito mucho sobre el tema, en esta investigación nos limitamos a presentar los puntos de vista de quienes hemos mencionado, admitiendo que muchos otros investigadores y escritos importantes están siendo omitidos.

43 Pinzani, A., "How much Schopenhauer is there really in Wagner?", en: Ethic@: An international Journal for Moral Philosophy, v. XI, 2 (2012), p. 219.
} 
más común para después rebatirla: que la influencia de Schopenhauer se atribuye a que Tristán e Isolda parece ser un claro ejemplo de la metafísica del amor sexual de la que se habla en El mundo como voluntad y representación. Gran parte de la labor de Pinzani es demostrar los inconvenientes de dicha interpretación y concluirá que solo Parsifal parece ser un personaje de influencia schopenhaueriana ${ }^{44}$. La presente investigación no se contrapone a las demostraciones que ofrece Pinzani, sino a la idea de que la influencia de Schopenhauer en Tristán e Isolda debe buscarse en el libreto o en sus personajes. La propuesta de esta investigación es precisamente buscar a Schopenhauer en la música de Tristán e Isolda, no en su libreto ${ }^{45}$.

Más arriba se dijo que Wagner fue influenciado principalmente por la metafísica de Schopenhauer. Dicha aclaración es necesaria porque la música de Wagner no era, en lo absoluto, la clase de música que le gustaba a Schopenhauer, quien se interesó "poco o casi nada por la obra de Wagner, pues consideraba que este tenía un don auténtico (aunque menor) para la poesía, y al escuchar El holandés errante y Tannhäuser concluyó que, como compositor, Wagner carecía de interés"46.

Sin embargo, en esta investigación la relación entre el pensamiento de Schopenhauer y la obra de Wagner se analiza de forma unidireccional, lo que quiere decir que solo se enfoca en lo que el compositor extrajo del filósofo y no en lo que el filósofo pensaba del compositor. Esto debido a que, en primer lugar, el filósofo no conoció la obra de Tristán e Isolda (que es la que nos ocupa en este momento); en segundo lugar, a que el hecho de que a Schopenhauer le gustara o no la obra wagneriana no es un factor determinante en la forma en que Wagner acogió el pensamiento schopenhaueriano y, en tercer lugar, a que los comentarios que hizo al respecto nunca mostraron un rechazo o contraposición entre su pensamiento y el de Wagner (más bien fueron juicios de gusto). A decir verdad, no parece que Wagner tuviera la intención de escribir música que le hubiera gustado a Schopenhauer, sino música que expresara su metafísica: "lo que [Wagner] asimiló y metabolizó hasta convertirlo en su

\footnotetext{
44 Cabe aclarar que Pinzani sí aborda la relación de los pasajes sobre música de El mundo como voluntad y representación con la peculiar composición musical de Tristán e Isolda. Piensa que "El famoso Acorde de Tristán probablemente está inspirado en la visión schopenhaueriana de la música” (Pinzani, A., "How much Schopenhauer is there really in Wagner?", p. 218).

${ }^{45}$ Aunque una exposición del libreto de Tristán e Isolda habría enriquecido el presente trabajo, debido a los fines de esta investigación y al tema central de la misma, se ha optado por dejar dicha labor a futuras investigaciones. Para conocer sobre el libreto de Tristán e Isolda y su contexto histórico, cf., Newman, E., The Wagner Operas, Princeton: Princeton University Press, 1991.

46 Magee, B., Schopenhauer, p. 363.
} 
propio tejido vital fueron sus doctrinas relacionadas con la ontología, la ética y la estética -la distinción entre el nóumeno y los fenómenos-, y conceptos como la levedad del mundo de los fenómenos, el carácter inevitable de la frustración, el sufrimiento y la muerte dentro de dicho mundo, la identidad nóumenal del todo, la tragedia de la individualización y el deseo de volver a una unidad global, la muerte como redención de la levedad del mundo de los fenómenos, y por lo tanto la negación de la voluntad de vivir como logro supremo de una conciencia individual; la compasión como base de la moral, la significación nóumenal de las artes y del sexo, y la condición singular de la música entre todas las artes, como expresión directa de la voluntad metafísica"47.

El pensamiento de Wagner tuvo interesantes transformaciones después de conocer la filosofia de Schopenhauer. En 1849 pensaba que la revolución podía destruir todo lo que oprime y hace sufrir a la humanidad y que de las ruinas de un mundo viejo podía surgir uno nuevo "lleno de felicidad nunca imaginada"48; que no se debian "formular definiciones abstractas sobre la naturaleza [del arte] sino entender su significado como un factor de la vida en común y analizarlo en cuanto producto social" 49 y que la música era "la línea divisoria entre la danza y la palabra, sensación y pensamiento"50. En 1870, después de haber leído a Schopenhauer, Wagner expondrá una concepción muy diferente del mundo, del arte, de la música y hasta del sufrimiento en su ensayo Beethoven: "[La música] es la inmediata manifestación de la unidad de la voluntad, su unión con la naturaleza por medio del sonido. Solo una condición puede sobrepasarla: lo sacro... el músico, con su excitante clarividencia, altera la consciencia individual y permite pensar en la experiencia mística, que eleva al sujeto más allá de todo límite. De este último grado del místico sufrimiento, con su condición espiritual, que nos encanta inefablemente, el antes desvalorizado músico recupera la honra perdida ante los otros artistas, gracias a su resplandeciente pretensión de sacralidad, pues su arte se relaciona en verdad con el complejo de las demás artes como la religión con la Iglesia. Lo que percibe su clarividencia no se puede expresar en ningún otro lenguaje" ${ }^{51}$.

Lo cierto es que la idea de Schopenhauer había germinado en el pensamiento de Wagner desde mucho antes. En diciembre de 1854, en una carta

\footnotetext{
${ }^{47}$ Ibid., p. 364.

${ }^{48}$ Wagner, R., Arte y Revolución, Madrid: Casimiro, 2013.

49 Ibid.

${ }^{50}$ Ibid.

${ }^{51}$ Wagner, R., Beethoven, p. 46.
} 
dirigida a Franz Liszt, Wagner confiesa que la lectura de Schopenhauer llegó a su soledad "como un regalo del cielo". En esa misma carta, le comenta a su amigo sobre un trabajo que tiene en mente: Tristán e Isolda, "la concepción musical más simple, pero también la más vigorosa" ${ }^{52}$. En enero de 1857 (cuando ya había dedicado gran parte de su tiempo a la composición de Tristán e Isolda), le escribe una carta a Marie Wittgenstein, donde afirma que dicho drama era, "solo música hasta ahora" 53 .

Sobre la concepción de Tristán e Isolda, Wagner explica en su autobiografia lo siguiente: "Como me ocurría habitualmente en el caso de una ocupación musical permanente, volvió a presentarse el impulso para una concepción poética. Lo que me inspiró la concepción de un Tristán e Isolda fue en parte, seguramente, el serio estado de ánimo en que me había puesto Schopenhauer, que ahora me apremiaba a una expresión extática de sus elementos fundamentales" 54 .

En Tristán e Isolda la influencia de Schopenhauer puede tener dos dimensiones: poética y musical ${ }^{55}$, aunque, como ya vimos, hay quienes niegan encontrarla en el libreto56. "Desde el punto de vista musical, es esencialmente diferente a cualquier otra composición del propio Wagner y a las de otros compositores de su tiempo" 57 y uno de los elementos fundamentales para sostener lo anterior es el ya mencionado Acorde de Tristán que deja ver, desde el inicio del drama, una composición innovadora en muchos sentidos ${ }^{58}$. Tristán e Isolda es un drama basado en la suspensión o retardo, un recurso musical que se ocupa para generar cierta tensión prolongando la nota de un acorde mientras las demás cambian. Recordemos lo que dice Schopenhauer sobre el retardo: "Es una disonancia que retrasa la consonancia final esperada con certeza, de modo que el deseo de ella se intensifica y su llegada nos satisface más: una clara analogía de la satisfacción de la voluntad aumentada por el retraso" 59 .

\footnotetext{
52 Magee, B., Wagner y la filosofia, p. 212.

53 Ibid.

54 Wagner, R., Mi vida, p. 464.

55 Cf., Brener, M., Wagner and Schopenhauer, 2014.

56 Tal es el caso del ya nombrado Alessandro Pinzani en su artículo "How much Schopenhauer is there really in Wagner?".

57 Pinzani, A., "How much Schopenhauer is there really in Wagner?", p. 218. La traducción es mia.

58 Cf., Magee, B., Wagner y la filosofia, 2011 y Brener, M., Wagner and Schopenhauer, 2014.

59 Schopenhauer, A., El mundo como voluntad y representación, v. II, p. 521.
} 
Vayamos ahora con Wagner en busca del retardo, pero esta vez no buscaremos en su autobiografia una constancia de la influencia de Schopenhauer, sino directamente en su obra musical, en el Acorde de Tristán:

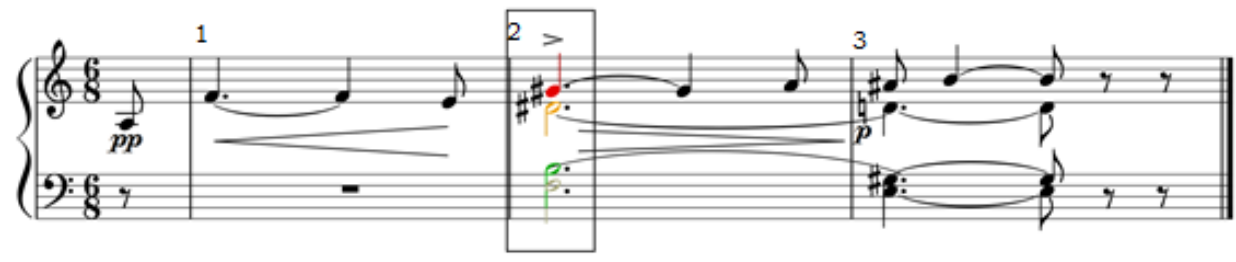

Ilustración 2: Acorde de Tristán (Versión para piano)

Imagen creada con MuseScore (2017)

La suspensión puede verse en la Ilustración 2, en el paso del Acorde de Tristán (ubicado en el segundo compás y señalado por un rectángulo) al siguiente acorde. Todas las notas cambian, excepto la segunda voz (marcada con amarillo), generando una tensión que no permite la resolución "total" del discurso musical. Schopenhauer también dice que: "La cadencia perfecta requiere la precedencia del acorde de séptima sobre la dominante, pues la satisfacción sentida en lo más profundo, y el completo reposo, solo pueden seguir al deseo más apremiante. Así pues, la música consiste en un cambio ${ }^{60}$ constante de acordes más o menos inquietantes, es decir, estimulantes deseos, y acordes más o menos tranquilizadores y placenteros. De igual manera, la vida del corazón (la voluntad) es un continuo intercambio entre la mayor o menor inquietud que nos causan el deseo o el miedo, con una dosis igualmente distinta de satisfacción. Y el desarrollo armónico consiste en la alternancia de la disonancia y la consonancia conforme a las reglas del arte musical" ${ }^{\prime}$.

Ya puede verse por qué Tristán e Isolda se considera un drama de influencia schopenhaueriana. Su estructura se basa en la idea de que, en un acorde, la voz superior se mueve "con libertad y sin trabas en el continuo ordenado, ininterrumpido y pleno de significado de un único pensamiento desde el comienzo hasta el fin". Además, el Acorde de Tristán es precisamente una

\footnotetext{
${ }^{60}$ En la traducción de Rafael-José Díaz y Montserrat Armas, en este pasaje, "Wechsel" se tradujo como "intercambio". Pilar López de Santa Maria traduce la misma palabra del mismo pasaje como "alternancia". En el presente trabajo se tradujo como "cambio" con el fin de mantener mayor claridad en los términos musicales.

${ }^{61}$ Schopenhauer, A., El mundo como voluntad y representación, v. II, p. 522.
} 
séptima de dominante con quinta disminuida, por lo que al caer en el siguiente acorde la satisfacción puede percibirse "más apremiante". El paso al siguiente acorde (que también es una séptima de dominante) deja sin resolver al primero, manteniendo así una tensión, como el cumplimiento de un deseo que solo nos satisface momentáneamente. Este pasaje musical (Ilustración 2), que es una buena muestra de lo que hace Wagner a lo largo del drama Tristán e Isolda, está basado en una suspensión (retardo) perpetua, es decir, el drama es en sí mismo una suspensión que solo se resuelve en el último acorde (cuando Isolda se une a su amado Tristán en la muerte).

El Acorde de Tristán implica "una seductora obsesión por transgredir la ortodoxia de la armonía, toda una filosofia inspirada en el valor sensual de los acordes inestables e irresueltos, que excitan más que satisfacen, que acumulan energía dilatando hasta el infinito su liberación"62, es una apuesta por convertir las palabras de Schopenhauer en música, por dejar al descubierto la forma en que opera la voluntad, por exponer una especie de decadencia que solo puede culminar en la muerte. Nietzsche afirmará que el filósofo de la decadencia (Schopenhauer) se dio a sí mismo el artista de la decadencia (Wagner) ${ }^{63}$. El Acorde de Tristán está precisamente "diseñado no para conducir tus oídos por una autovía musical bien señalizada sino para asomarte a un abismo cuya mística solo se resuelve en una muerte que les toma a [Tristán y a Isolda] casi cinco horas"64. Bryan Magee afirma que el drama Tristán e Isolda puso claramente el sistema tonal bajo amenaza y a lo largo de las siguientes décadas tal amenaza se materializó. La obra subsecuente de Wagner empujó la tonalidad hasta sus límites más extremos: el último acto de su última ópera, Parsifal, abre con un preludio de la orquesta, algunas de cuyas partes no pueden asignarse a ningún tono en particular ${ }^{65}$.

\section{Conclusión: La idea afortunada hecha música}

Esta investigación, como se dijo, fue una aventura basada en una propuesta aventurada: descubrir la influencia de la filosofia de Schopenhauer en la composición musical del drama Tristán e Isolda de Richard Wagner. Descubrimos que todo inició con una única idea afortunada de Schopenhauer,

\footnotetext{
${ }^{62}$ Bayón, F., "El acorde de Tristán o la música del porvenir", Wordpress, El Castillo de Barbazul (blog), 25 de octubre de 2011.

${ }^{63}$ Nietzsche, F., Escritos sobre Wagner, Madrid: Biblioteca Nueva, 2003.

${ }^{64}$ Bayón, F., "El acorde de Tristán o la música del porvenir".

${ }^{65}$ Magee, B., Wagner y la filosofia, p. 217.
} 
resistente y extremadamente contagiosa; luego, esa idea se adhirió con fuerza a la ideologia de Wagner y a su manera de ver el mundo, por lo que fue imposible erradicarla de su mente y de sus obras posteriores, una vez que fue completamente entendida se quedó ahí, en alguna parte, en alguna nota, en algún acorde. Esa idea es: El mundo es mi voluntad y mi representación. Tristán e Isolda es el intento de expresar la metafisica de Schopenhauer en forma de música.

$\mathrm{Si}$ el arte es un reflejo de la sociedad y su interacción con el mundo, afirmar que Schopenhauer sembró la idea que germinó en la composición musical de Tristán e Isolda no suena tan disparatado. A fin de cuentas, su filosofia expresa una forma en que el hombre es en el mundo y cómo ve el mundo. Si el mundo es un mar de continuo sufrimiento donde pasamos de un deseo a otro sin encontrar nunca satisfacción; si el mundo es un lugar sin centro, sin fin último, sin intencionalidad y sin embargo lleno de tensiones emocionales. ¿Cómo será la música de semejante mundo? Deberá ser, necesariamente, llena de tensiones, llena de retardos que alargan la espera, un continuo pasar de un acorde disonante a otro igual de disonante que solo nos mantiene a la expectativa hasta llegar a la barra final. ¿Qué habría pensado Schopenhauer de que su filosofía pudo ser la causante de que la música se volviera todavía un reflejo más fiel del mundo que él mismo describió?

Recibido: 10/06/2018

Aceptado: 09/10/2019

\section{Bibliografia}

Bayón, F., "El acorde de Tristán o la música del porvenir", Wordpress, El Castillo de Barbazul (blog), 25 de octubre de 2011. https://disfrutarlaopera.wordpress. com/2011/10/25/el-acorde-de-tristan-o-la-musica-del-porvenir/

Brener, Milton E., Wagner and Schopenhauer: a Closer Look, Xlibris LLC, 2014.

Janaway, Ch., Schopenhauer: A Very Short Introduction, Nueva York: Oxford University Press, 2002. https://doi.org/10.1093/actrade/9780192802590.001.0001

Magee, B., Schopenhauer, Madrid: Cátedra, 1991.

Magee, B., Wagner y la filosofía, México: Fondo de Cultura Económica, 2011.

Millet, J., "Una perspectiva sobre la filosofia de la música", en: Teorema: Revista internacional de filosofia, v. XXXI, 3 (2012), pp. 5-24.

Moncada, F., La más sencilla, útil y práctica teoría de la música, México: Ediciones Framong Musical Iberoamericana, 1966.

Newman, E., The Wagner Operas, Princeton: Princeton University Press, 1991. 
Nietzsche, F., Escritos sobre Wagner, Madrid: Biblioteca Nueva, 2003.

Nolan, Ch. (director y escritor), Inception, 35mm, Warner Brothers, 2010 (filme). http:// www.imdb.com/title/tt1375666/

Pérez, E., El Wagner de las ideologías: Nietzsche-Wagner, Madrid: Biblioteca Nueva, 2004.

Philonenko, A., Schopenhauer: una filosofia de la tragedia, Barcelona: Anthropos, 1989.

Pinzani, A., "How much Schopenhauer is there really in Wagner?", en: Ethic@: An international Journal for Moral Philosophy, v. XI, n. 2, (2012). https://doi. org/10.5007/1677-2954.2012v11nesp1p211

Safranski, R., Romanticismo: una odisea del espíritu alemán, México: Tusquets, 2009.

Schopenhauer, A., El mundo como voluntad y representación, v. I, Madrid: Gredos, 2014.

Schopenhauer, A., El mundo como voluntad y representación, v. II, Madrid: Gredos, 2014.

Wagner, R., Arte y Revolución, Madrid: Casimiro, 2012.

Wagner, R., Beethoven, Madrid: Fórcola, 2016.

Wagner, R., Mi vida, Madrid: Turner, 1989. 